\title{
MULTI-CRITERIA DECISION MAKING METHODS FOR COMPARING THREE MODELS OF ALUMINUM INGOT PRODUCTION THROUGH LIFE CYCLE ASSESSMENT
}

\author{
ZARE, R. ${ }^{1}$ - IZADIKHAH, M. ${ }^{2 *}$ \\ ${ }^{1}$ Department of Environmental Management, Faculty of Medical Sciences, Arak Branch, \\ Islamic Azad University; Arak 38135/567, Iran \\ e-mail: r-zare@iau-arak.ac.ir \\ ${ }^{2}$ Department of Mathematics, College of Science, Arak Branch, Islamic Azad University \\ Arak 38135/567, Iran \\ *Corresponding author \\ e-mails: m-izadikhah@iau-arak.ac.ir; m_izadikhah@yahoo.com \\ phone: +98-918-364-1752 \\ (Received $17^{\text {th }}$ Feb 2017; accepted $4^{\text {th }}$ May 2017)
}

\begin{abstract}
The aim of this study is to compare the potential environmental impacts of three kinds of aluminum: primary aluminum ingot (A), secondary aluminum ingot (B) and to mix aluminum ingot (C) with each other. For this purpose, the life cycle assessment model is developed based on damage oriented approach. For each unit process, the reference flow is $500 \mathrm{~kg}$. The results show that model "A" has the highest impacts in all categories, model " $\mathrm{B}$ " is intermediate and the model " $\mathrm{B}$ " is the most environmentally friendly process. As a surprising result model " $\mathrm{B}$ " has the highest amount for fluoride, BTEX and VOC compared with the models "A" and "C" as air emission. Finally with regard to all aspects, model "B" or mixed aluminum is selected as the preferable option. The most important reasons for this selection are energy savings, low refining required and low demand for specially landfill operation with regarding Iran as a developing country. Also we examine further this subject by applying the Entropy and ELECTRE methods.
\end{abstract}

Keywords: environment, secondary aluminum, primary aluminum, LCA, Entropy method, ELECTRE method

\section{Introduction}

Aluminum is widely used in transportation, building, packaging, consumer durables, and many other sectors (Sheller, 2014; Wang and Graedel, 2010; Bergsdal et al., 2004). Also production and consumption of aluminum will undoubtedly keep growing, mainly driven by developing countries (Moors, 2006). The increases for aluminum production in the Middle East are projected to spread across more countries, including Iran, Saudi Arabia, and the United Arab Emirates (Menzie et al., 2010). The production of aluminum from bauxite requires much more energy than many other metals and causes large amounts of greenhouse gas (GHG) emissions) (Zhang et al., 2014; Shao et al., 2014; Norgate and Rankin, 2002; Norgate et al., 2007). However, the global aluminum industry has reduced its emissions such as perfluorocarbons (PFCs) in past years. Again the aluminum production almost has doubled at the same time. Therefore, these pollutants are released and continue to contaminate the environment (Liu and Müller, 2012). Aluminum is either produced from bauxite (primary) or from scrap (secondary). Secondary aluminum is produced from scrap in refiners and remelters. Refiners produce casting alloys and deoxidation aluminum mainly from old scrap (i.e., post-consumer scrap): remelters produce wrought or master alloys mainly from clean and sorted new 
scrap (i.e., pre-consumer scrap) (Boin and Bertram, 2005; Liu and Müller, 2012). The main influence for the environmental impacts related to aluminum production was the energy source and these impacts varied from $2 \mathrm{~kg} \mathrm{CO}$ eq. $\mathrm{kg}^{-1}$ of recycled aluminum to $22.5 \mathrm{~kg} \mathrm{CO}$ eq. $\mathrm{kg}^{-1}$ of primary aluminum in Asia as a result of use of coal for electricity generation (McMillan, 2011; McMillan and Keoleian, 2009). Thereupon, recycling of aluminum from scrap requires almost 20 times less energy than primary production Liu and Müller (2012). The total global energy use for secondary production should be about $1 \%$ of primary production, therefore, $0.01 \%$ of global total energy use van der Voet (2013). The use of recycled aluminum cuts raw material inputs and decrease waste outputs and land use for landfill sites de Schrynmakers (2009). In this study, the life cycle assessment (LCA) method used for to compare the environmental impacts of three different paths to produce aluminum ingot. LCA is a systematic method that addresses the environmental aspects and potential environmental impacts throughout a product's life cycle from raw material acquisition through production, use, end of life treatment, recycling and final disposal (Klöpffer, 2014; ISO, 2006). As an important environmental decision supporting tool, LCA has already been widely used in the aluminum industry (Chang et al., 2012; Hong et al., 2012; Frees, 2008; Olivieri et al., 2006; Rebitzer and Buxmann, 2005; Liu and Müller, 2012). Globally, aluminum production is responsible for about $1 \%$ of the annual GHG emissions (IEA, 2009) and in sum, $19 \mathrm{~kg} \mathrm{CO}$ eq. $\mathrm{kg}^{-1}$ emitted for global marginal primary aluminum production trades in a global market (Sevigné-Itoiz et al., 2014). For these reasons, aluminum LCAs are very sensitized to about where primary or recycled aluminum is applied (Hatayama et al., 2009; Ding et al., 2012; Liu and Müller, 2012; Rombach, 2013). Both problem-oriented (mid-points) and damage-oriented (end-points) LCIA methods are used in the studies aluminum LCAs Liu and Müller, (2012). Until now, no case studies regarding the production of aluminum in the Iran country have been published. The aim in this study is to compare the potential cradle-to-gate environmental impacts of " $A$ ", "B" and "C" models. Hence a life cycle assessment model was developed using SimaPro8.0 software PRe Consultants (2013). It can be used to compare different aluminum production routes for a product. The studied aluminum production process is based on variation of raw materials, where these materials are found on a combination of primary and secondary aluminum with different percentages. In the LCA model, the environmental loads of the different plants for the production of $500 \mathrm{~kg}$ of aluminum metal were investigated. The impact of the aluminum production was assessed in three impact categories and ten impact indicators.

Besides the above analysis on evaluating the potential environmental impacts of three models; primary aluminum ingot (A), secondary aluminum ingot (B) and to mix aluminum ingot $(\mathrm{C})$ we present some extra discussions based on multiple attributes decision making problems (Izadikhah et al., 2014). In order to have an in-depth discussion we apply the well-known Entropy method (Shannon, 2001) for deriving the weights of criteria in each assessment. This method can efficiently evaluate the average essence of information quantity and the larger the entropy value, the lower the information express quantity. Then we use the obtained weights to rank and compare the three above mentioned kinds of aluminums. For this purpose we apply the ELECTRE method (Roy, 1985; Roy and Bouyssou, 1993). This method is based on the concept of ranking by paired comparisons between alternatives on the appropriate criteria. 
This paper unfolds as follows: In Secton 2, the required mathematical background is presented. Section 3 briefly reviews the material and methods. Section 4 shows the studied processes. Results and analysis are appeared in Section 5. In Section 6, some discussion is presented. In Section 7 conclusions are given.

\section{Mathematical background}

In order to do an in-depth analysis, we need to review some important mathematical method.

\section{Entropy weighting method and Shannon entropy}

Shannon (2001) proposed the entropy concept, which is a measure of uncertainty in information formulated in terms of probability theory. Since the entropy concept is well suited for measuring the relative contrast intensities of criteria to represent the average intrinsic information transmitted to the decision maker (Zeleny, 1982). The entropy weighting method (Zeleny, 1982) can effectively measure the average essence of information quantity and the larger the entropy value, the lower the information express quantity (Feng and Chen, 1992). So it is a suitable means to calculate the weights of criteria in any decision making problems (Salehi and Izadikhah, 2012). Thus, it can represent actual conditions of decision-making, and express the explanation ability and reliability of sub-criteria. The steps can be summarized as follows:

Step 1: Allow $x_{i j}, i=1,2 \ldots, m ; j=1,2 \ldots, n$, to be the superiority rating of the $i^{\text {th }}$ alternative under $j^{\text {th }}$ criterion above the alternative level. Then we can define:

$$
X=\left[x_{i j}\right]_{m \times n} \quad i=1, \ldots, m ; j=1, \ldots, n
$$

and we call $X$ as decision matrix.

Step 2: Form normal decision matrix $R=\left[r_{i j}\right]_{m \times n}$, where

$$
\forall i, j ; \quad r_{i j}=\frac{x_{i j}}{\sum_{i=1}^{m} x_{i j}}
$$

Step 3: Calculation of concentration index for per criteria's data as follows,

$$
E_{j}=-\frac{1}{\ln (m)} \sum_{i=1}^{m} r_{i j} \ln \left(r_{i j}\right), \quad j=1, \ldots, n
$$

The lower value for $E_{j}$ implies less concentration of data $C_{j}$ criteria and more dispersal of its data.

Step 4: Determination the amount of per criteria's Dispersal. The amount of per criteria's Dispersal calculated as following: 


$$
d_{j}=1-E_{j}, \quad j=1, \ldots, n
$$

Step 5: Calculation the weight of criteria. The weight of criteria calculated as following:

$$
w_{j}=\frac{d_{j}}{\sum_{j=1}^{n} d_{j}} \quad j=1, \ldots, n
$$

Therefore, we have $0 \leq w_{j} \leq 1, \quad j=1, \ldots, n$.

\section{The ELECTRE methods}

The ELECTRE (Elimination Et Choix Traduisant He realite) is based on the concept of ranking by paired comparisons between alternatives on the appropriate criteria (see Roy, 1985; Roy and Bouyssou, 1993). An alternative is said to dominate the other alternatives if one or more criteria are met (compared with the criterion of other alternatives) and it is equal to the remaining criteria (see also Barba-Romero and Pomerol, 1997; Romero, 1993).

The ELECTRE methodology is based on the concordance and discordance indices defined as follows. We start from the data of the decision matrix, and assume here that the sum of the weights of all criteria equals to 1 . For an ordered pair of alternatives $\left(\mathbf{A}_{j}, \boldsymbol{A}_{k}\right)$, the concordance index $c_{j k}$ is the sum of all the weights for those criteria where the performance score of $\mathbf{A}_{j}$ is least as high as that of $\boldsymbol{A}_{k}$, i.e.

$$
c_{j k}=\sum_{i: a_{i j} \geq a_{i k}} w_{i}, \quad j, k=1, . ., n, j \neq k .
$$

Clearly, the concordance index lies between 0 and 1 . The computation of the discordance index $d_{j k}$ is a bit more complicated: $d_{j k}=0$ if $a_{i j}>a_{i k}, i=1, \ldots, m$, i.e. the discordance index is zero if $\mathbf{A}_{j}$ performs better than $\boldsymbol{A}_{k}$ on all criteria,. Otherwise,

$$
d_{j k}=\max _{i=1, . ., m} \frac{a_{i k}-a_{i j}}{\max _{j=1, . . n} a_{i j}-\min _{j=1, \ldots, n} a_{i j}}, \quad j, k=1, . ., n, j \neq k,
$$

i.e. for each criterion where $\boldsymbol{A}_{k}$ outperforms $\mathbf{A}_{j}$, the ratio is calculated between the difference in performance level between $\boldsymbol{A}_{k}$ and $\mathbf{A}_{j}$ and the maximum difference in score on the criterion concerned between any pair of alternatives. The maximum of these ratios (which must lie between 0 and 1) is the discordance index. A concordance threshold $c^{*}$ and discordance threshold $d^{*}$ are then defined such that $0<d^{*}<\mathrm{c}^{*}<1$. Then, $\mathbf{A}_{j}$ outranks $\boldsymbol{A}_{k}$ if the $c_{j k}>c^{*}$ and $d_{j k}<d^{*}$, i.e. the concordance index is above and the discordance index is below its threshold, respectively. This outranking defines a partial ranking on the set of alternatives. Consider the set of all alternatives that outrank at least one other alternative and are themselves not outranked. This set contains the promising alternatives for this decision problem. Interactively changing the level thresholds, we also can change the size of this set. 


\section{Material and methods}

Here a case study on aluminum industries in Arak industrial city in Iran is presented. Aluminum ingot and production mix are considered as unit function. The aluminum production process includes bauxite mining, alumina production, anode plant, electrolysis process and casting process. Ingots are providing to this life-cycle stage from both primary and secondary aluminum processing. For each unit process, the reference flow is $500 \mathrm{~kg}$. In this research, the energies that mainly used for mix aluminum ingot production are electricity, natural gas and heavy oil. SimaPro8.0.4 education software and Ecoindicator99 impact assessment methodology is used to perform a numerical analysis of the cradle-to-gate life cycle of aluminum, for three models. Environmental data on unit processes are collected by using the Ecoinvent 3 datasets. This study qualifies as an attributional LCA, as it describes the environmentally relevant physical flows to and from the processes associated with the life cycle of the mix aluminum ingots, in this case from cradle-to-gate in different three models (three kinds of aluminum) that denoted with model "A", model "B" and model "C". In this case, data for bauxite mining, alumina production, anode production, electrolysis, primary ingot casting and secondary aluminum processing integrates into LCI unit. The impact of the aluminum production is assessed in three impact categories. The quality of the LCI data for modeling the life cycle stages in this research has been assessed according to ISO 14044 (ISO, 2006). Endpoint and midpoint categories based on Eco-indicator method are represented in Table 1. The midpoint is combined into three damage or endpoint categories including: i) Human health; measured in DALY (Disability Adjusted Life Years) which is a measure of the disability caused by different environmental impacts on human health ii) Ecosystem quality; which are measured in $\mathrm{PDF} * \mathrm{~m}^{2} /$ year (Potentially Disappeared Fraction of plant species) iii) Resources; measured in MJ surplus.

\section{Studied processes}

\section{Bauxite mining}

Bauxite Mining begins with the removal of overburden from a bauxite-rich mining site. The operations associated with this unit process include: extraction of bauxite-rich minerals from the site, beneficiation activities (washing, screening, or drying), treatment of mining site residues and waste and site restoration activities (grading, dressing, and replanting). The output of this unit process is the bauxite that is transported to an alumina production plant.

\section{Alumina production}

Alumina production process include: bauxite grinding, digestion, and processing of liquors, alumina precipitation and calcination, maintenance and repair of plant and equipment, treatment of process air, liquids, and solids. The output of this unit process is smelter-grade alumina transported to primary aluminum smelters. In alumina refining, air emissions arise from the calcination stage such as: particulates; $\mathrm{NO}_{\mathrm{x}}$, as $\mathrm{NO}_{2}$ and $\mathrm{SO}_{2}$ from fuel combustion; mercury found in bauxite ores, while water emissions come from cooling use such as: water, oil / grease or are linked with the digestion stage such as: suspended solids, mercury found in bauxite ores. Most of the bauxite residue currently turns out as solid waste, while a small but growing fraction is 
reused. Other by-products for external recycling are reaction chemicals. Other landfill wastes are typically inert components from bauxite, such as sand, or waste chemicals.

Table 1. Endpoint and midpoint categories based on Eco-indicator99

\begin{tabular}{|c|c|c|c|}
\hline Endpoint category & Unit & Midpoint indicators & Unit \\
\hline human health & DALY & radiation & DALY \\
\hline ecosystem quality & PDF* $\mathrm{m}^{2} \mathrm{yr}$ & ozone layer & DALY \\
\hline resources & MJ surplus & eco-toxicity & PDF* $^{2} \mathrm{yr}$ \\
\hline Midpoint indicators & & acidification/ & \multirow{2}{*}{$\mathrm{PDF}^{*} \mathrm{~m}^{2} \mathrm{yr}$} \\
\hline carcinogens & DALY & eutrophication & \\
\hline respirable organics & DALY & land use & PDF* $^{2} \mathrm{yr}$ \\
\hline respirable inorganics & DALY & minerals & MJ surplus \\
\hline climate change & DALY & fossil fuels & MJ surplus \\
\hline
\end{tabular}

\section{Anode production}

There are two types of aluminum smelting technologies including soderberg and prebake anode that is used in the reduction process. In this study we use the prebake anode technology. The prebake design has prefired blocks of solid carbon suspended from axial busbars. The busbars both hold the anodes in place and carry the current for electrolysis. Anode production process begins with the unloading of process materials to their storage areas on plant. The operations associated with this unit process include: recovery of spent anode materials, anode mix preparation; block forming and baking, rodding of baked anodes, maintenance and repair of plant and equipment and treatment of process air, liquids, and solids. The outputs of this unit process are anodes transported to a primary aluminum smelter.

It this process, including air emission can be noted fluoride related to recovered spent anode butts from electrolysis that are recycled within prebake anode production. Particulates, $\mathrm{NO}_{\mathrm{x}}$ and $\mathrm{SO}_{2}$ normally come from fuel combustion. Total polycyclic aromatic hydrocarbons (PAH), which include benzo-a-pyrene are air emissions arising from the basic anode production process. A common practice for their prevention and monitoring is water scrubbing. By-products for external recycling include the recovery of used steel from anode bars or used refractory material from baking furnaces. Various other by-products are also recovered, for example, carbon recovered for reuse. Solid waste that is landfilled includes waste carbon or a mixed residue from anode production, scrubbing used for control of air emissions mentioned previously, refractory waste from baking furnaces, and other landfill wastes that arise as various residues, for example, carbon fines. 


\section{Electrolysis}

Molten aluminum is produced from alumina by the electrolytic process. This involves two steps: dissolving the alumina in a molten cryolite bath and passing electric current through this solution, thereby decomposing the alumina into aluminum and oxygen. The operations associated with this unit process include: recovery, preparation, and handing of process materials, manufacture of major process equipment, process of control activities including metal, bath, heat, maintenance and process repair of equipment and treatment of process air, liquids, and solids. Alumina is converted in the primary aluminum smelting by the following reaction:

$$
2 \mathrm{Al}_{2} \mathrm{O}_{3}+3 \mathrm{C}=4 \mathrm{Al}+3 \mathrm{CO}_{2}
$$

The output of this unit process is hot metal transported to an ingot casting plant. Air emissions from this process are fluoride, which generated from the molten bath; Total polycyclic aromatic hydrocarbons, including benzo-a-pyrene, which arises from anode consumption; and $\mathrm{CF}_{4}$ and $\mathrm{C}_{2} \mathrm{~F}_{6}$, typically reported as perfluorocarbons, that are gases generated with an abnormally anode overvoltage situation called anode effect. Particulates, $\mathrm{NO}_{\mathrm{x}}$, and $\mathrm{SO}_{2}$, commonly come from fuel combustion. Fluoride and total polycyclic aromatic hydrocarbons arise from the same origin as their aforesaid air emission equivalents and are monitored in water discharges. Suspended solids and oil and grease and maybe total hydrocarbons are monitored in water discharges from wet scrubbing. On the other hand, landfill wastes typically consist of approximately $75 \%$ environmental abatement waste and $25 \%$ municipal waste. Aluminum smelters use some type of air pollution control system to reduce emissions. The primary system is dry scrubber, with alumina as the absorbent. The alumina is then returned to the post as feedstock. This allows recovery of the scrubbed materials. Dry scrubbers absorb the emitted carbon dioxide, nitrogen oxide, and sulfur dioxide.

\section{Primary aluminum ingot casting}

Ingot casting as unit process include: Pretreatment of hot metal including cleaning and auxiliary heating, recovery and handling of internal process scrap, batching, metal treatment, and casting operations, sawing, and packaging and casting operations, maintenance and repair of equipment and treatment of process air, liquids, and solids. The output of this unit process is packaged aluminum ingots. When the alloying is completed, the melt is fluxed to remove impurities and reduce gas content. In this case, the used chlorine results in hydrogen chloride. It is considering for air emissions. Fluxing removes entrained gases and inorganic particulates by flotation to the metal surface. These impurities or dross are skimmed off.

\section{Secondary aluminum processing}

The life-cycle stage of secondary aluminum processing includes the unit processes of manufacturing scrap transport, consumer scrap transport, shredding, decoating, and secondary ingot casting. 


\section{Results and analysis}

\section{The goal and scope definition}

In this study we compare the potential cradle-to-gate environmental impacts of three models of aluminum ingot production based on required raw materials. The production of aluminum ingot starting from the transformation of bauxite to alumina, the process of conversion of alumina to aluminum, and the final cast product and the process of refining and the production of secondary aluminum ingots are studied using a Life Cycle Assessment (LCA) approach. The presented models for $500 \mathrm{~kg}$ mixed aluminum ingot includes primary and secondary aluminum with a certain proportion is implemented in Arak-Iran. These models are as follows:

The model 1: In this model, ingot production process is accomplished with $95 \%$ primary aluminum and denote with " $\mathrm{A}$ ". In the model " $\mathrm{A}$ ", with the focus on primary aluminum production, share of primary production process is only $5 \%$.

The model 2: In the proposed model, ingot production process is accomplished with $95 \%$ secondary aluminum and 5\% primary aluminum that denote with " $\mathrm{B}$ ". In the model "B", with the focus on secondary aluminum production, share of primary production process is only $5 \%$.

The model 3: In this model, $65 \%$ of the total system is related to primary aluminum facilities, and the remaining $35 \%$ is related to secondary aluminum facilities. Proposed model is denoting with " $\mathrm{C}$ ".

\section{Life cycle inventory}

Inventory data associated with the research models are shown in Table 2. These data are complemented by LCI data in the SimaPro8.0.4 software. The process is the same for "A", "B" and "C" models, but with different values of inputs and outputs. Model "B" (using aluminum scrap and slag) shows a significant decrease in energy and raw material and emissions compared with the other models as " $A$ " and " $C$ ". The environmental impacts of primary aluminum ingot (model " $\mathrm{A}$ ") are, mainly due to consumption of electricity $31500 \mathrm{MJ}$. These impacts for model " $\mathrm{B}$ " and "C" are due to approximately $1660 \mathrm{MJ}$ and $21600 \mathrm{MJ}$ respectively, for $500 \mathrm{~kg}$ aluminum ingot. Also, based on the results of study, the non-aluminum-containing part of the bauxite is disposed of as bauxite residue (red mud, "A"; $941 \mathrm{~kg}$, "B"; $49.6 \mathrm{~kg}$ "C"; $644 \mathrm{~kg}$ ). As Table 1 shows the emission of $\mathrm{CO}_{2}$ at model " $\mathrm{A}$ " $(9443 \mathrm{~kg})$ is about thirteen that of the model " $\mathrm{B}$ " $(820 \mathrm{~kg})$ and is more than one and a half times of model "C" $(6569 \mathrm{~kg})$. The emission of $\mathrm{SO}_{2}$ at model " $\mathrm{A}$ " is $41.6 \mathrm{~kg}$, the model " $\mathrm{B}$ " $4.4 \mathrm{~kg}$ and at the model "C" $29.2 \mathrm{~kg}$. As a result of the unusual, model "B" (using aluminum scrap and slag) shows a significant increase in fluoride, BTEX (Benzene, Toluene, Ethylbenzene, and Xylene, (unspecified ratio) and VOC (volatile organic compounds) compared with the models "A" and "C" (fluoride; 6.74094*10 $0^{-8}$ versus $3.54786 * 10^{-9}$ and $2.4835^{*} 10^{-8} \mathrm{~kg}$, BTEX; 0.0275 versus 0.0014 and $0.0101 \mathrm{~kg}$ and VOC; $0.0771,0.0041$ and $0.0284 \mathrm{~kg}$ respectively). Fig. 1 presents cut from map for $500 \mathrm{~kg}$ mixed Aluminum including $65 \%$ primary and 35\% secondary aluminum ingot process (Model "C"-LCA-SimaPro software). 


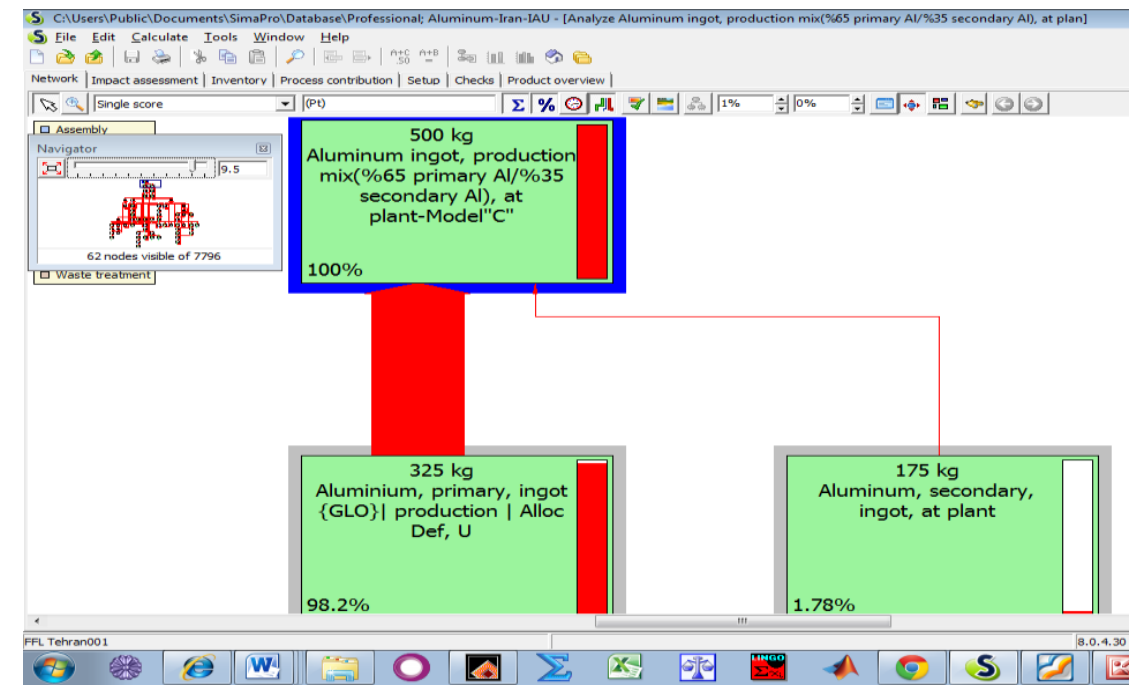

Figure 1. Cut from map for $500 \mathrm{~kg}$ aluminum mix (65\% primary/35\% secondary) (SimaPro software)

\section{Life cycle impact assessment}

The main purpose of this phase is to evaluate the amount and significance of potential environmental impacts, arising from the set of results of the phase of inventory analysis (ISO, 2006). The elements of this phase are: selection of impact categories, classification, characterization and normalization (optional). Environmental impacts related to production of $500 \mathrm{~kg}$ the mix aluminum ingot for " $\mathrm{A}$ ", " $\mathrm{B}$ " and " $\mathrm{C}$ " models are presented in Fig. 2, based on endpoint categories. When using characterization to compare results, the process with the highest impact to a category is set to be $100 \%$ and then the impacts from the other processes is measured according to this. As it can be seen, resources category the make up the greatest contribution, for all the three models with $0.100 \%, 70 \%$ and $9 \%$ respectively. This damage category covers all natural resources as fossil and minerals (Table 1). This is due to the greater proportion of molten aluminum required as an input example, the main source of energy resources depletion in model "A" is the power plant with 62.8\% (31500 MJ surplus). Furthermore, the human health category has a major share in environmental impacts related to " $\mathrm{A}$ ", "B" and " $\mathrm{C}$ " models respectively. Resp. inorganics, climate change and carcinogens indicators are the consequences of this the damage categories. Finally, the endpoint category of ecosystem quality with $100 \%\left(310.85, \mathrm{PDF}^{*} \mathrm{~m}^{2} / \mathrm{yr}\right) 69 \%(23.32$, $\left.\mathrm{PDF} * \mathrm{~m}^{2} / \mathrm{yr}\right)$ and $8 \%\left(215.01, \mathrm{PDF} * \mathrm{~m}^{2} / \mathrm{yr}\right)$ respectively, in the three models involved. The ecosystem quality is insignificant in the studied processes.

Fig. 3 presents the normalized results of environmental impacts related to production of $500 \mathrm{~kg}$ the mix aluminum ingot for " $\mathrm{A}$ ", "B" and "C" models, based on midpoint indicators. As figure shows, for all of the studied models, respirable inorganics ("A"; 0.005546, "B"; 0.000471 "C"; 0.003854 DALY), climate change ("A"; 0.002136, "B"; 0.00019 "C"; 0.0015 DALY), carcinogens "A"; 0.0023 , "B"; 0.0001 "C"; 0.0016 DALY) and fossil fuels ("A",19186 "B"; 1829 "C"; $13400 \mathrm{MJ}$ surplus) are the most affected midpoint categories. 
Table 2. Inputs and outputs for $500 \mathrm{~kg}$ mixed aluminum ingot production

\begin{tabular}{|c|c|c|c|c|}
\hline Inputs & Unit & Model "A"1 & Model "B"2 & Model "C" ${ }^{\prime 3}$ \\
\hline \multicolumn{5}{|l|}{ Raw materials } \\
\hline Bauxite & & 1610 & 124 & 961 \\
\hline Natural gas & $\mathrm{M}^{3}$ & 2489 & 271 & 1750 \\
\hline Electricity & MJ & 31500 & 1660 & 21600 \\
\hline \multicolumn{5}{|l|}{ Outputs } \\
\hline \multicolumn{5}{|l|}{ Air emissions } \\
\hline Carbon dioxide, fossil & $\mathrm{kg}$ & 9443 & 820 & 6569 \\
\hline Sulfur dioxide & $\mathrm{kg}$ & 41.6 & 4.4 & 29.2 \\
\hline Nitrogen oxides & $\mathrm{kg}$ & 19.68 & 1.51 & 13.62 \\
\hline Fluoride & $\mathrm{kg}$ & $3.54786 \mathrm{E}-09$ & $6.74094 \mathrm{E}-08$ & $2.4835 \mathrm{E}-08$ \\
\hline Hydrogen fluoride & & 2.52 & 0.13 & 1.72 \\
\hline NMVOC & $\mathrm{kg}$ & 4.37 & 0.30 & 3.01 \\
\hline VOC & $\mathrm{kg}$ & 0.0041 & 0.0771 & 0.0284 \\
\hline PAH & & 0.01250 & 0.00067 & 0.00856 \\
\hline $\mathrm{PM}_{2.5-10}$ & $\mathrm{~kg}$ & 1.24 & 0.08 & 0.85 \\
\hline $\mathrm{PM}_{>2.5}$ & $\mathrm{~kg}$ & 1.50 & 0.09 & 0.3 \\
\hline $\mathrm{PM}_{<10}$ & $\mathrm{~kg}$ & 1.97 & 0.11 & 1.35 \\
\hline BTEX & $\mathrm{kg}$ & 0.0014 & 0.0275 & 0.0101 \\
\hline Hydrogen chloride & $\mathrm{kg}$ & 0.23 & 0.01 & 0.16 \\
\hline \multicolumn{5}{|l|}{ Water emissions } \\
\hline BOD5 & $\mathrm{kg}$ & 8.20 & 0.53 & 5.64 \\
\hline COD & $\mathrm{kg}$ & 17.70 & 1.08 & 12.16 \\
\hline Arsenic & $\mathrm{kg}$ & 0.0316 & 0.0018 & 0.0217 \\
\hline Cadmium & $\mathrm{kg}$ & 0.00180 & 0.00015 & 0.00128 \\
\hline \multicolumn{5}{|c|}{ 1. Aluminum mix (95\% primary aluminum / 5\% secondary aluminum) } \\
\hline \multicolumn{5}{|c|}{ 2. Aluminum mix (95\% primary aluminum / 5\% secondary aluminum) } \\
\hline \multicolumn{5}{|c|}{ 3. Aluminum mix ( $95 \%$ primary aluminum / 5\% secondary aluminum) } \\
\hline \multicolumn{5}{|c|}{ 4. non-methane volatile organic compounds, unspecified origin } \\
\hline \multicolumn{5}{|c|}{ 5. volatile organic compounds } \\
\hline \multicolumn{5}{|c|}{ 6. polycyclic aromatic hydrocarbons } \\
\hline \multicolumn{5}{|c|}{ 7. Benzene, Toluene, Ethylbenzene, and Xylene, (unspecified ratio) } \\
\hline \multicolumn{5}{|c|}{ 8. Biological-Oxygen-Demand } \\
\hline \multicolumn{5}{|c|}{ 9. Chemical Oxygen Demand } \\
\hline
\end{tabular}

Also, in minerals category, model " $\mathrm{A}$ " has the highest resources effect due to aluminum (1533 MJ surplus), cupper (39.92 MJ surplus), and nickel (19.27 MJ surplus). On the other hand, when compared with the other options, the environmental impact of the model " $A$ " is more sensitive to changes carcinogens category. All models show approximately the same trend for midpoint categories, so that in this connection, resp. organics, radiation, ozone layer, acidification / europhication, ecotoxicity and land use have little impact on models. Overall, model "A" has the highest impacts in the all 
categories, model " $\mathrm{B}$ " is intermediate and the model " $\mathrm{B}$ " is the most environmentally friendly process. Although in some cases model " $\mathrm{C}$ " can also be appropriate option specially, compared to model "A". This process has a clear main advantage of low energy use and Less waste production in the aluminum scrap refinery plant compared to the model " $\mathrm{A}$ " and model "C". The main disadvantage related to model " $\mathrm{C}$ " is the high consumption raw materials and energy compared to the model "B".

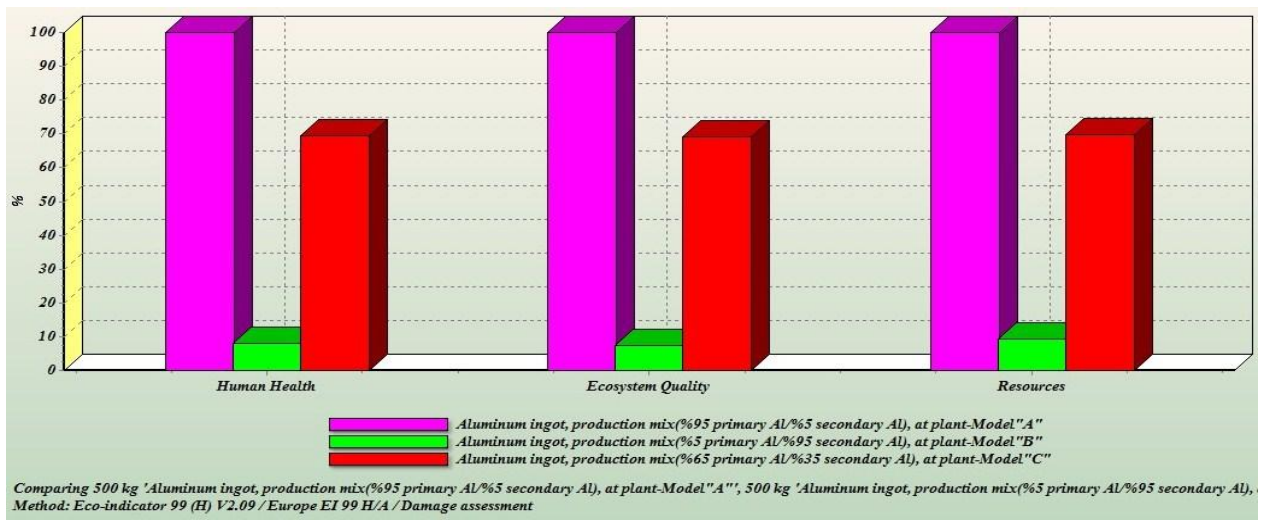

Figure 2. Results of endpoint categories for $500 \mathrm{~kg}$ the mixed aluminum models

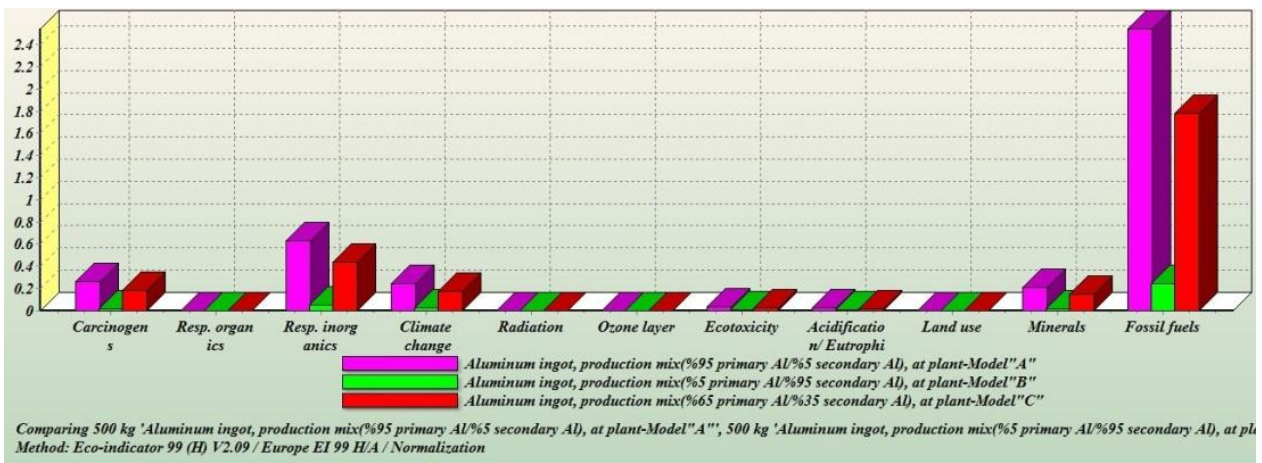

Figure 3. Normalized results for $500 \mathrm{~kg}$ the mixed aluminum models, based on midpoint categories

Relative contributions to environmental impacts related to production $500 \mathrm{~kg}$ aluminum mix (65\% primary / 35\% secondary), based on human health damage category are presented in Fig. 4. the total human health from aluminum production in model "C" is 0.00693 DALY. Emissions to air are mainly as $\mathrm{SO}_{2} 0.00160$ DALY, $\mathrm{CO}_{2}$ 0.00137 DALY and $\mathrm{NO}_{\mathrm{x}} 0.00120$ DALY. Also water emission is arsenic 0.00142 DALY. These values for two other options as model "A"; 0.00227, 0.00198, 0.00174 and 0.00207 DALY respectively and model "B"; 0.00024, 0.00017, 0.00013 and 0.00012 DALY respectively. 


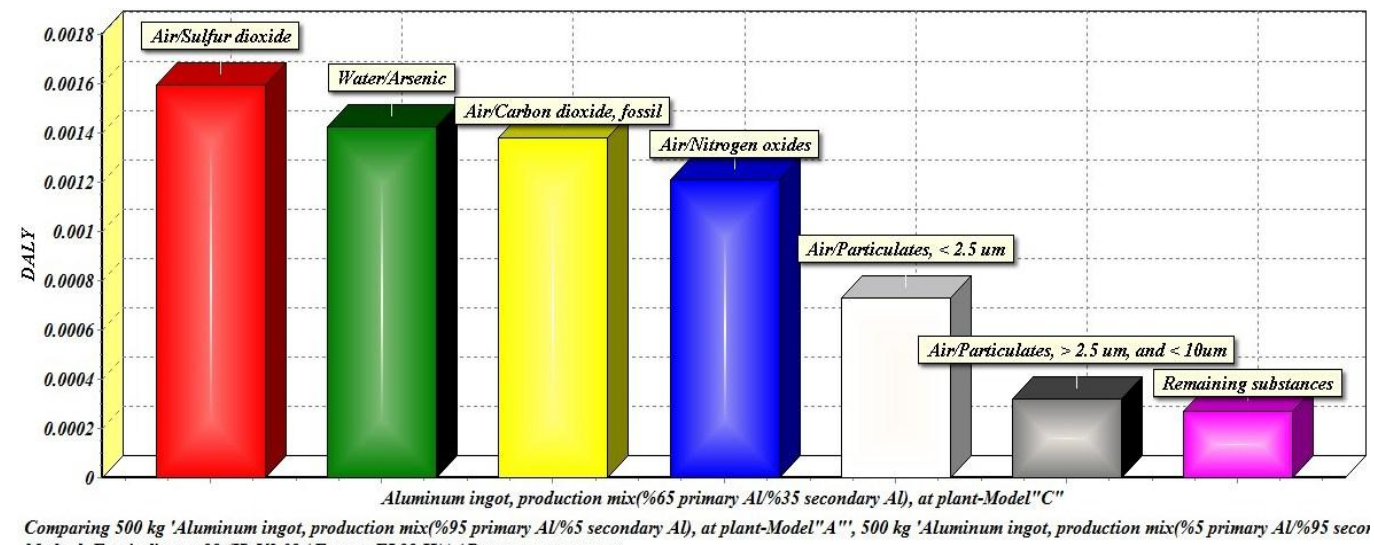
Method: Eco-indicator 99 (H) V2.09/ Europe EI $99 \mathrm{H} / \mathrm{A} /$ Damage assessment

Figure 4. Results of environmental impacts for $500 \mathrm{~kg}$ aluminum mix (65\% primary / 35\% secondary), based on human health category.

Environmental impacts related to production $500 \mathrm{~kg}$ model "C" by resp. inorganics category is presented in Fig. 5. Total resp. inorganics as an indicator per $500 \mathrm{~kg}$ aluminum produced model " $\mathrm{A}$ " is 0.0038 DALY while this indicator in the model " $\mathrm{A}$ " and " $\mathrm{B}$ " models is 0.0055 and 0.0005 DALY respectively. As can be observed, $\mathrm{SO}_{2}$ with $0.0016, \mathrm{NO}_{\mathrm{x}}$ with 0.0012 and total particles with 0.0007 make up the greatest contributions, respectively in term of DALY (to compare, model "A"; $\mathrm{SO}_{2}$ with 0.0022 , $\mathrm{NO}_{\mathrm{x}}$ with 0.0017 and total particles with 0.0015 and model "B"; $\mathrm{SO}_{2}$ with $0.0002, \mathrm{NO}_{\mathrm{x}}$ with 0.0001 and total particles with $9.22 * 10^{-5}$ ).

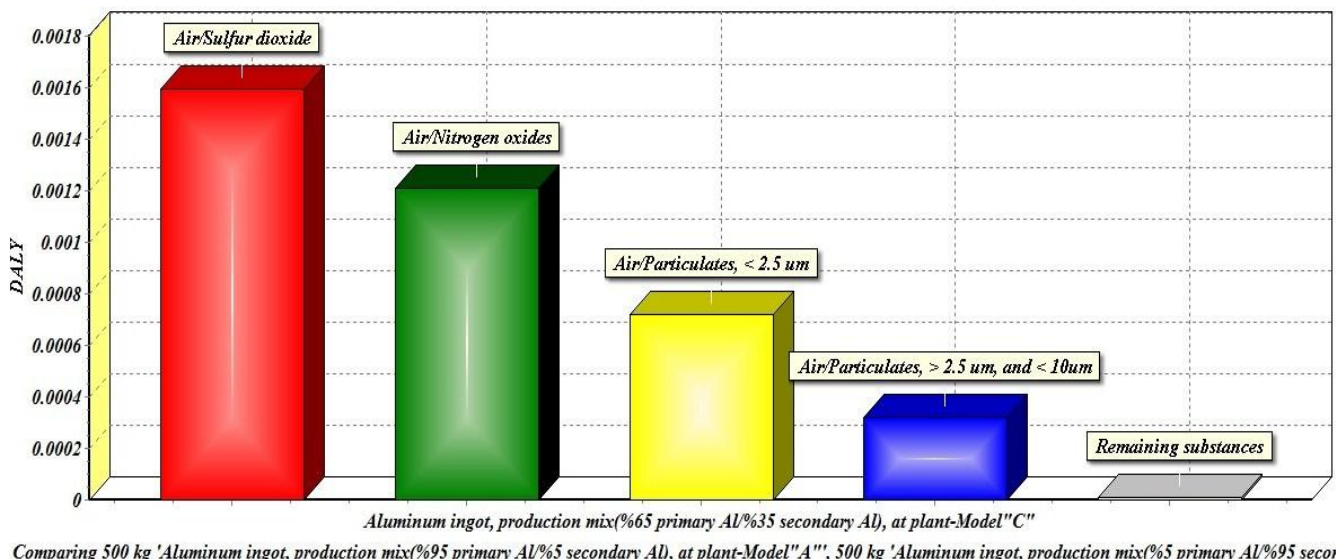
Method: Eco-indicator 99 (H) V2.09/ Europe EI 99 H/A / Characterization

Figure 5. Results of environmental impacts for $500 \mathrm{~kg}$ Aluminum mix (65\% primary / 35\% secondary), based on resp. inorganics category.

Fig. 6 presents the environmental impacts related to production $500 \mathrm{~kg}$ model "C" by carcinogens category. In this model, the total inorganics as an indicator is 0.0016 DALY, about $32 \%$ less than the model "A" and 91\% more than model "B". Fig. 6 shows that the emissions constituent at the model " $\mathrm{C}$ " the most to inorganics is arsenic with 0.0014 DALY. In this case, model " $C$ " is upper than model " $\mathrm{B}$ " (0.0001 DALY) and lower than model "A" (0.0020 DALY). Fig. 7 shows environmental impacts related to production $500 \mathrm{~kg}$ model " $\mathrm{C}$ " by climate change category. The $\mathrm{CO}_{2}$ is the greatest 
contributor to the climate change category of all studied models; "A", "B", "B" with $0.0020,0.0002$ and 0.0014 respectively in terms of DALY. In the climate change category, model "A" and model "B" have the highest and the lowest impact for aluminum ingot production. Again, model " $\mathrm{C}$ " is intermediate.

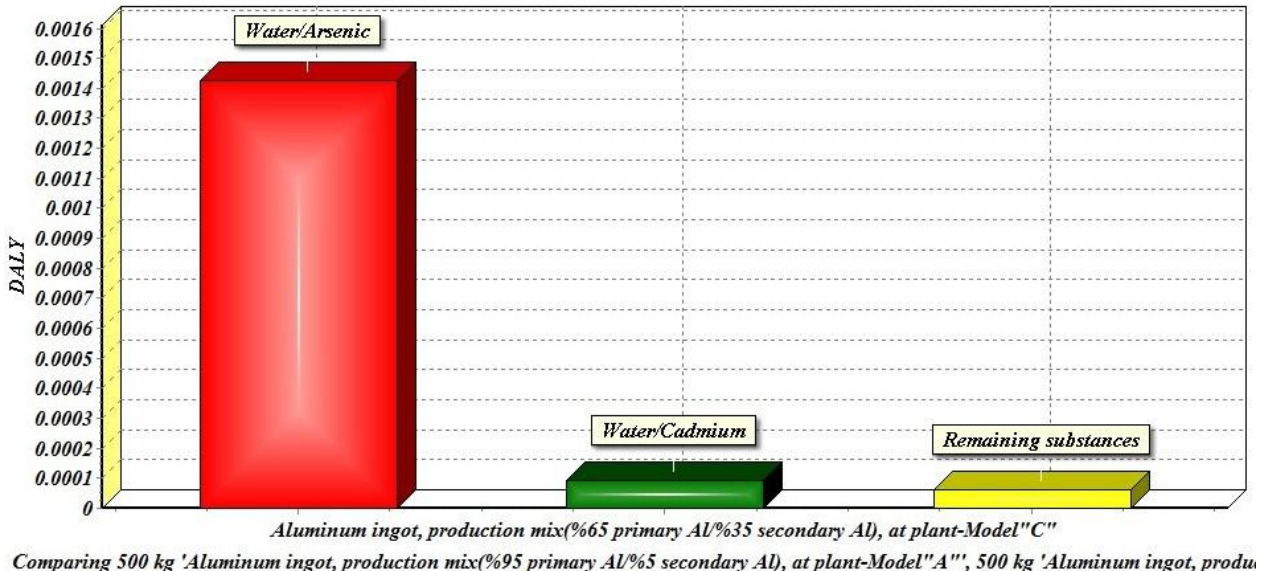

Comparing $500 \mathrm{~kg}$ 'Aluminum ingot, production mix(\%95 primary AL\%5 secondary Al), at plant-Model"A"', $500 \mathrm{~kg}$ 'Aluminum ingot, produ Method: Eco-indicator 99 (H) V2.09 / Europe EI 99 H/A / Characterization

Figure 6. Results of environmental impacts for $500 \mathrm{~kg}$ aluminum mix $(65 \%$ primary $135 \%$ secondary), based on carcinogens category.

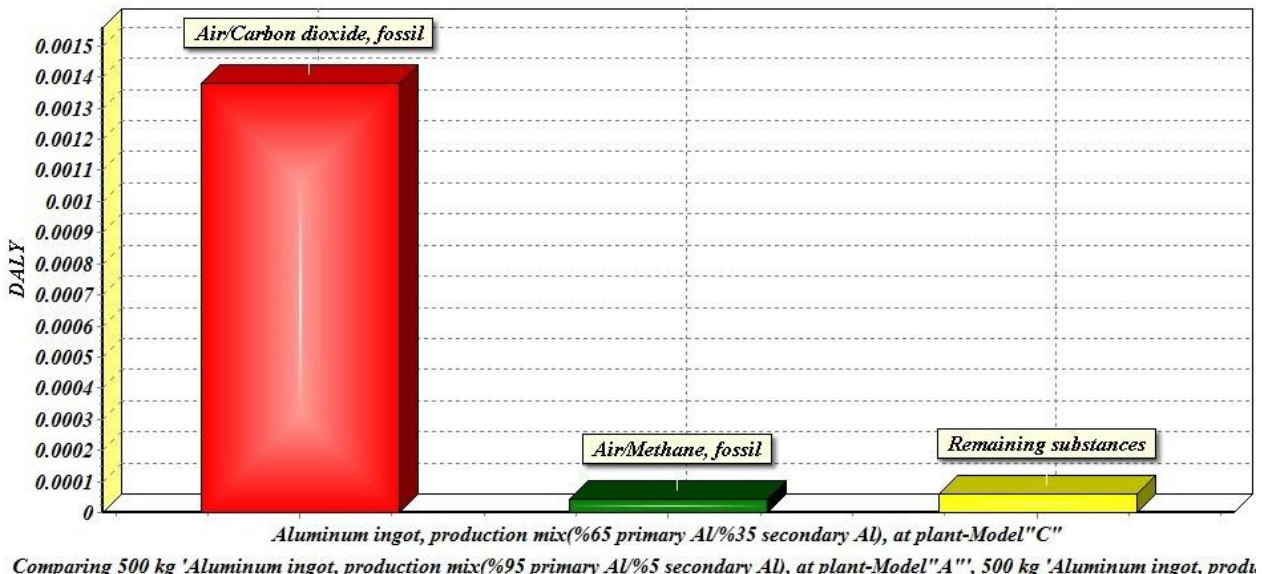

Comparing $500 \mathrm{~kg}$ 'Aluminum ingot, production mix(\%95 primary AV\%5 secondary Al), at plant-Model"A"', $500 \mathrm{~kg}$ 'Aluminum ingot, produ Method: Eco-indicator 99 (H) V2.09/Europe EI 99 H/A / Characterization

Figure 7. Results of environmental impacts for $500 \mathrm{~kg}$ aluminum mix (65\% primary / $35 \%$ secondary), based on climate change category.

\section{Further analysis based on Entropy and ELECTRE}

By means of Entropy and ELECTRE methods we compare and rank the materials Al Mix-A, Al Mix-B and Al Mix-C in three aspects: i) with respect to damage category criteria, ii) with respect to air emissions criteria, iii) with respect to water emissions criteria.

\section{Analysis based on damage category criteria}

According to Tables 1 and 2 there are eleven criteria that form damage category criteria. Since there aren't any default weights or decision maker's opinion we use the 
Entropy method. Table 3 shows the obtained weights of damage category's criteria based on Entropy method.

Table 3. Obtained weights of damage category's criteria based on Entropy method

\begin{tabular}{|c|c|c|c|c|c|c|}
\hline & $\mathbf{W}_{\mathbf{1}}$ & $\mathbf{W}_{\mathbf{2}}$ & $\mathbf{W}_{\mathbf{3}}$ & $\mathbf{W}_{\mathbf{4}}$ & $\mathbf{W}_{\mathbf{5}}$ & $\mathbf{W}_{\mathbf{6}}$ \\
\hline \multirow{2}{*}{ Weights } & 0.09702 & 0.088394 & 0.085606 & 0.084667 & 0.096859 & 0.097012 \\
\hline & $\mathrm{W}_{7}$ & $\mathrm{~W}_{8}$ & $\mathrm{~W}_{9}$ & $\mathrm{~W}_{10}$ & $\mathrm{~W}_{11}$ & \\
\cline { 1 - 5 } Weights & 0.09405 & 0.085579 & 0.100072 & 0.081501 & 0.08924 & \\
\hline
\end{tabular}

The obtained weights are almost close to each other. We expected to see this result because the data of Table 2 were relatively close to each other. From Table 3, it is clear that the criterion "Minerals" has the biggest weight among all criteria. By means of these weights we apply the ELECTRE method. Table 4 shows the obtained weighted decision matrix. From all criteria only the criterion "Land use" is a benefit criterion.

Table 4. Weighted decision matrix for damage category

\begin{tabular}{|c|c|c|c|c|c|c|}
\hline & C1 & C2 & $\mathrm{C} 3$ & C4 & C5 & C6 \\
\hline Al Mix-A & 0.079889214 & 0.072510208 & 0.070125185 & 0.069322 & 0.079752 & 0.079882 \\
\hline Al Mix-B & 0.004756462 & 0.00568234 & 0.00596111 & 0.006052 & 0.004775 & 0.004757 \\
\hline \multirow[t]{2}{*}{ Al Mix-C } & 0.054844963 & 0.050234252 & 0.04873716 & 0.048232 & 0.054759 & 0.054841 \\
\hline & C7 & C8 & C9 & C10 & C11 & \\
\hline Al Mix-A & 0.077349 & 0.070102 & 0.082499 & 0.066614 & 0.073234 & \\
\hline Al Mix-B & 0.005085 & 0.005964 & 0.00441 & 0.00635 & 0.005596 & \\
\hline Al Mix-C & 0.053261 & 0.048723 & 0.05647 & 0.046526 & 0.050688 & \\
\hline
\end{tabular}

The final calculation of the ELECTRE method concludes that:

$$
\text { Al Mix-B > Al Mix-C > Al Mix-A }
$$

That shows the Al-Mix B has the best effect with respect to damage category. 


\section{Analysis based on air emissions criteria}

According to Tables 1 and 2 there are thirteen criteria that form air emissions criteria. Again for making an analysis for the effects of these three materials on air emissions we use the Entropy method. Table 5 shows the obtained weights of air emissions criteria based on Entropy method.

Table 5. Obtained weights of air emissions criteria based on Entropy method

\begin{tabular}{|l|c|c|c|c|c|c|c|}
\hline & $\mathbf{W}_{\mathbf{1}}$ & $\mathbf{W}_{\mathbf{2}}$ & $\mathbf{W}_{\mathbf{3}}$ & $\mathbf{W}_{\mathbf{4}}$ & $\mathbf{W}_{\mathbf{5}}$ & $\mathbf{W}_{\mathbf{6}}$ & $\mathbf{W}_{\mathbf{7}}$ \\
\hline Weights & 0.061833966 & 0.056544545 & 0.064928 & 0.09022986 & 0.073651 & 0.067562 & 0.090002 \\
\hline & $\mathrm{W}_{8}$ & $\mathrm{~W}_{9}$ & $\mathrm{~W}_{10}$ & $\mathrm{~W}_{11}$ & $\mathrm{~W}_{12}$ & $\mathrm{~W}_{13}$ & \\
\cline { 1 - 6 } Weights & 0.072861 & 0.068997 & 0.113729 & 0.072036 & 0.0911 & 0.076526 & \\
\hline
\end{tabular}

From Table 5, it is clear that the criterion "PM $>2.5$ " has the biggest weight among all criteria. By means of these weights we apply the ELECTRE method. The final calculation of the ELECTRE method concludes that

$$
\text { Al Mix-B = Al Mix-C > Al Mix-A }
$$

That shows the Al-Mix B and Al-Mix C simultaneously have the best effect with respect to air emissions.

\section{Analysis based on water emissions criteria}

According to Tables 1 and 2 there are four criteria that form water emissions criteria. Again for making an analysis for the effects of these three materials on air emissions we use the Entropy method. Table 6 shows the obtained weights of water emissions criteria based on Entropy method.

Table 6. Obtained weights of water emissions criteria based on Entropy method

\begin{tabular}{|c|c|c|c|c|}
\hline & $\mathbf{W}_{\mathbf{1}}$ & $\mathbf{W}_{\mathbf{2}}$ & $\mathbf{W}_{\mathbf{3}}$ & $\mathbf{W}_{\mathbf{4}}$ \\
\hline Weights & 0.252113 & 0.256698 & 0.261947 & 0.229242 \\
\hline
\end{tabular}

From Table 6, it is clear that the criterion "PM $>2.5$ " has the biggest weight among all criteria. By means of these weights we apply the ELECTRE method. The final calculation of the ELECTRE method concludes that:

$$
\text { Al Mix-B = Al Mix-C > Al Mix-A }
$$

That shows the Al-Mix B and Al-Mix C simultaneously have the best effect with respect to water emissions. 
Fig. 8 illustrates the situation of each material with respect to all cases. It is clear that the Al Mix-B has the best effect on all cases.

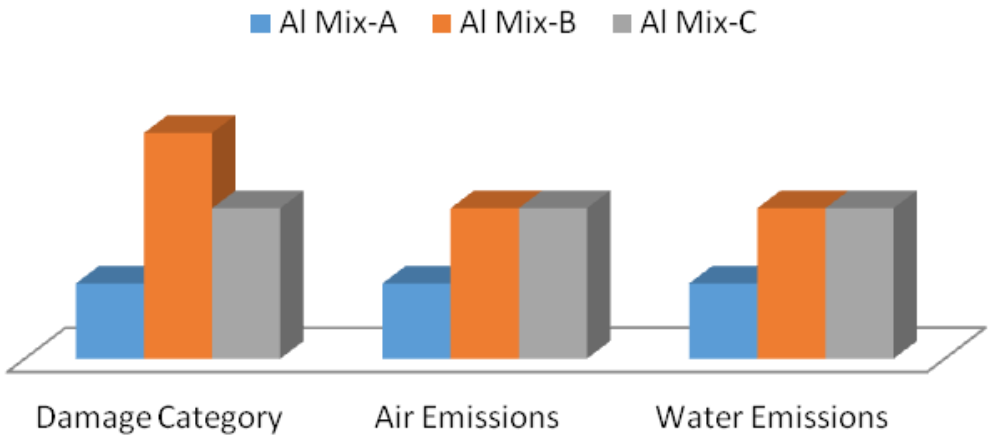

Figure 8. Comparison of the materials

\section{Discussion}

The main goal was to compare, by means of a LCA and MCDM methods, the potential environmental impacts of different aluminum ingot production processes. The study was a cradle-to-gate LCA, thus it ends at the factory gate, with the final product of mixed aluminum ingots ready for transport. According to the goal of this assessment, a primary aluminum production and a secondary production route and a mixed aluminum production are evaluated and the negative environmental impacts from the three production different routes were compared with each other. It was found that in " $A$ " and "C" model, electricity use is the main issue, and since the energy used is largely based on fossil fuels, this will have a large impact on for example climate change. The importance of recycled, or secondary aluminum in model " $\mathrm{B}$ " is expected to rise since its production requires less energy. "“A"; 19186 "B"; 1829 "C"C; $13400 \mathrm{MJ}$ surpluses). The fossil category at model " $\mathrm{B}$ " is $90.5 \%$ and $86 \%$ lower than that of " $\mathrm{A}$ " and "C" respectively. The difference of roughly $17000 \mathrm{MJ}$ model " $\mathrm{A}$ " with " $\mathrm{B}$ " is mainly attributable to the larger energy consumption for alumina refining by " $\mathrm{A}$ " model". In addition, the difference in midpoint categories such as resp. inorganics, carcinogens, climate change or fossil between the three models can be explained by important differences in emissions. For example, the $\mathrm{SO}_{2}$ emitted per $500 \mathrm{~kg}$ aluminum ingot at model " $\mathrm{A}$ " is about nine times the model " $\mathrm{B}$ " and one and a half times larger than model "A". This is about Arsenic (in water) and Cadmium (in water) also described as contributing factors for Carcinogens category. A surprising result from this comparison is that the secondary aluminum production (model " $\mathrm{B}$ ") has the highest amount fluoride, BTEX and VOC as air emissions compared to "A" and "C" models. Altogether according to what was described, it is found that the environmental impacts from the " $\mathrm{A}$ " are larger than from the " $\mathrm{B}$ " and " $\mathrm{C}$ ". The model " $\mathrm{A}$ " has the highest impacts. The result was predictable. The model " $\mathrm{C}$ " have the second highest impacts. This is not surprising since the finished alloy is composed of $65 \%$ primary aluminum and $35 \%$ scrap, and the high energy use during primary production is known. The model "B" using aluminum scrap and slag for ingot production generally having the lowest impacts to all categories. Fig. 2 shows that model "B", has the low environmental impact. This result was predictable, due to the very low energy use 
compared to the other options. Although, if we accept aluminum production in model " $B$ " is a method based on aluminum refinery outputs in plants that are based in a developing country, the result was perhaps another thing. Because, it is considered that model "B" uses less in Ecoinvent 3, Ecoindicator 99 and totally, in SimaPro8.0.4 package. Therefore, in real terms the situation may be different. In this case, aluminum scraps treatment in Arak industrial area mainly is doing by small businesses as refinery plants. In this plants, old scraps and aluminum slag typically, contains a lot of impurities and therefore, should be done on the purification process. Uncontrolled and hazardous wastes as output from the proposed refiners could bring high negative impacts for the environment. These plants do not have the facilities necessary for the implementation of environmental regulations and as a result, they choose the easiest way, is to ignore them. In small industries such as aluminum refinery plants, environmental requirements not to be applied to a variety of reasons; they do not have sufficient knowledge about the environmental consequences. Industries of interest do not benefit from integrated management and hence do not consider all aspects of the matter. Eventually, they do not have adequate financial resources and so not have long-term planning. Hence, model "B" was selected as the preferable option. The further analysis by means of the Entropy and ELECTRE methods confirmed this result. It can decrease raw materials need of the aluminum industry and to decrease energy consumption for the raw material production as well compared with " $\mathrm{A}$ ". On the other hand, mix aluminum production can decrease refining need related to old scraps and so decrease the amount of specific land filling compared with "B".

\section{Conclusion}

We applied the LCA methodology to evaluate options for ingot production process. We compared the results obtained for primary aluminum ingot (called model " $\mathrm{A}$ "), secondary aluminum ingot (called model " $\mathrm{B}$ ') and to mix aluminum ingot (called model " $C$ "') with each other. This comparison showed that model "A" have the highest impacts to all categories. A surprising result from this comparison was that the secondary aluminum production (model "B") has the highest amount for fluoride, BTEX and VOC as air emission. We considered various aspects to attainment the preference of the purposed models from the point of view of environmental issues in the decision-making process. These included the LCA results, the environmental impacts procurement and transportation of aluminum scrap and aluminum slag, the facilities and capabilities of refiners and eventually, the feasibility of the implementation of environmental regulations namely, wastewater treatment, air pollution control and landfilling by this plants. Finally, with regard to all aspects, we concluded that " $\mathrm{B}$ " is also considered to be relatively a friendly environment process. The most important reasons for selecting of model "B" or mixed aluminum were energy savings, low refining required and low demand for specially landfill operation with regarding Iran as a developing country. Besides the above analysis and for the purpose of have an indepth discussion we applied the Entropy method for deriving the weights of criteria in each assessment. Then we used the obtained weights to rank and compare the three kinds of aluminums. So, we applied the ELECTRE method. This complementary analysis proved that the aluminum model " $B$ " or mixed aluminum was the best. 


\section{REFERENCES}

[1] Barba-Romero, S., Pomerol, J. C. (1997): Decisiones Multicriterio Servicio de Publicaciones. - Universidad de Alcalá, Alcalá de Henares.

[2] Bergsdal, H., Strømman, A. H., Hertwich, E. G. (2004): The aluminium industryenvironment, technology and production. - Norwegian University of Sciences and Technology, Industrial Ecology Programme, Trondheim, Norwey.

[3] Boin, U. M. J., Bertram, M. (2005): Melting standardized aluminum scrap: A mass balance model for europe. - JOM 57(8): 26-33.

[4] Chang, Y.-J., Schau, E. M., Finkbeiner, M. (2012): Application of Life Cycle Sustainability Assessment to the bamboo and aluminum bicycles in surveying social risks of developing countries. - Paper presented at the 2nd World Sustainability Forum, Technische Universität Berlin, Germany.

[5] de Schrynmakers, P. (2009): Life cycle thinking in the aluminium industry. - The International Journal of Life Cycle Assessment 14(1): 2-5.

[6] Ding, N., Gao, F., Wang, Z., Gong, X., Nie, Z. (2012): Environment impact analysis of primary aluminum and recycled aluminum. - Procedia Engineering 27: 465-474.

[7] Feng, C. M., Chen, C. F. (1992): The determination of criteria weights-compromised weighting method. - Traffic and Transportation 14: 51-67.

[8] Frees, N. (2008): Crediting aluminium recycling in LCA by demand or by disposal. - The International Journal of Life Cycle Assessment 13(3): 212-218.

[9] Hatayama, H., Daigo, I., Matsuno, Y., Adachi, Y. (2009): Assessment of the recycling potential of aluminum in Japan, the United States, Europe and China. - Materials Transactions 50(3): 650-656.

[10] Hong, J., Zhou, J., Hong, J., Xu, X. (2012): Environmental and economic life cycle assessment of aluminum-silicon alloys production: a case study in China. - Journal of Cleaner Production 24: 11-19.

[11] IEA. (2009): Energy technology transitions for industry: strategies for the next industrial revolution. - OECD Publishing, Organisation for Economic Co-operation Development, France.

[12] ISO 14040. (2006): Environmental management-Life cycle assessment-Principles and framework. - ISO, Geneva.

[13] Izadikhah, M., Saeidifar, A., Roostaee, R. (2014): Extending TOPSIS in fuzzy environment by using the nearest weighted interval approximation of fuzzy numbers. Journal of Intelligent \& Fuzzy Systems 27: 2725-2736.

[14] Klöpffer, W. (2014): Background and Future Prospects in Life Cycle Assessment. Springer Science \& Business Media.

[15] Liu, G., Müller, D. B. (2012): Addressing sustainability in the aluminum industry: a critical review of life cycle assessments. - Journal of Cleaner Production 35: 108-117.

[16] McMillan, C. A. (2011): Modeling temporal aluminum material flows and greenhouse gas emissions to evaluate metals recycling allocation in life cycle assessment. University of Michigan, USA.

[17] McMillan, C. A., Keoleian, G. A. (2009): Not all primary aluminum is created equal: Life cycle greenhouse gas emissions from 1990 to 2005. - Environmental science \& technology 43(5): 1571-1577.

[18] Menzie, W., Barry, J., Bleiwas, D., Bray, E., Goonan, T., Matos, G. (2010): The global flow of aluminum from 2006 through 2025. - US Geological Survey, Reston, Virginia.

[19] Moors, E. H. M. (2006): Technology strategies for sustainable metals production systems: a case study of primary aluminium production in The Netherlands and Norway. - Journal of Cleaner Production 14(12-13): 1121-1138.

[20] Norgate, T., Jahanshahi, S., Rankin, W. (2007): Assessing the environmental impact of metal production processes. - Journal of Cleaner Production 15(8): 838-848. 
[21] Norgate, T., Rankin, W. (2002): The role of metals in sustainable development. - Green Processing 2002 : International Conference on the Sustainable Processing of Minerals. 29-31 May, 2002, Cairns, Queensland.

[22] Olivieri, G., Romani, A., Neri, P. (2006): Environmental and economic analysis of aluminium recycling through life cycle assessment. - International Journal of Sustainable Development \& World Ecology 13(4): 269-276.

[23] PRe Consultants, B. (2013): SimaPro 8 user's manual. - The Netherlands.

[24] Rebitzer, G., Buxmann, K. (2005): The role and implementation of LCA within life cycle management at Alcan. - Journal of Cleaner Production 13(13-14): 1327-1335.

[25] Rombach, G. (2013): Raw material supply by aluminium recycling - Efficiency evaluation and long-term availability. - Acta Materialia 61(3): 1012-1020.

[26] Romero, C. (1993): Teoría de la decisión multicriteria: Conceptos,técnicas y aplicaciones. - Alianza Universidad Textos, Madrid.

[27] Roy, B. (1985): Méthodologie Multicritère d'Aide à la Décision. - Economica, Paris.

[28] Roy, B., Bouyssou, D. (1993): Aide Multicritère à la Décision: Méthodes et cas. Economica, Paris.

[29] Salehi, A., Izadikhah, M. (2012): A novel method to extend SAW for decision-making problems with interval data. - Decision Science Letters 3: 225-236.

[30] Sevigné-Itoiz, E., Gasol, C. M., Rieradevall, J., Gabarrell, X. (2014): Environmental consequences of recycling aluminum old scrap in a global market. - Resources, Conservation and Recycling 89: 94-103.

[31] Shannon, C. E. (2001): A mathematical theory of communication. - ACM SIGMOBILE Mobile Computing and Communications Review 5(1): 3-55.

[32] Shao, C., Guan, Y., Wan, Z., Chu, C., Ju, M. (2014): Performance analysis of $\mathrm{CO}_{2}$ emissions and energy efficiency of metal industries in China. - Journal of Environmental Management 134: 30-38.

[33] Sheller, M. (2014): Aluminum Dreams: The Making of Light Modernity. - MIT Press, Cambridge.

[34] Van der Voet, E., Salminen, R., Eckelman, M., Norgate, T., Mudd, G., Hisschier, R., Spijker, J., Vijver, M., Selinus, O., Posthuma, L., De Zwart, D., Van de Meent, D., Reuter, M., Tikana, L., Valdivia, S., Wäger, P., Hauschild, M. Z., De Koning, A. (2013): Environmental risks and Challenges of anthropogenic metals flows and cycles. - United Nations Environment Progrtamme, Technical University of Denmark, Denmark.

[35] Wang, J., Graedel, T. (2010): Aluminum in-use stocks in China: a bottom-up study. Journal of Material Cycles and Waste Management 12(1): 66-82.

[36] Zeleny, M. (1982): Multiple Criteria Decision Making. - McGraw-Hill, New York.

[37] Zhang, W., Li, H., Chen, B., Li, Q., Hou, X., Zhang, H. (2014): $\mathrm{CO}_{2}$ emission and mitigation potential estimations of China's primary aluminum industry. - Journal of Cleaner Production 103: 863-872. 